\title{
Differing perspectives on what is important in media reporting of suicide ${ }^{\dagger}$
}

Jane Pirkis and Anna Machlin

\section{Summary}

There is a substantial literature which demonstrates that irresponsible reporting of suicide can lead to copycat acts and, as a result, many countries have developed guidelines for media professionals. Some of the recommendations in these guidelines draw directly on the evidence and describe how reporting can be done in a measured fashion that minimises any likely negative influence. Other recommendations relate more to good journalistic practice and are about showing respect for the bereaved in their time of grieving. The study by Chapple et $\mathrm{al}$, in this issue, indicates that there may sometimes be tensions between what media guidelines recommend and what those bereaved by suicide believe is important. We would argue that in such cases common ground can be reached.

\section{Declaration of interest}

None.
Jane Pirkis (pictured) is the Director of the Centre for Health Policy, Programs and Economics at the University of Melbourne. She has conducted extensive research in the area of suicide and the media. Anna Machlin is a Research Fellow in the Centre for Health Policy, Programs and Economics at the University of Melbourne. She is currently working on a number of projects on media reporting of suicide.

The study by Chapple et al, ${ }^{1}$ in this issue, makes an important contribution to the literature on suicide and the media by seeking the perspective of those who have lost a loved one to suicide. It explored the perceptions of 40 bereaved individuals of the media reporting that occurred in the aftermath of the death. Some of these individuals had been interviewed by the journalists who prepared the stories. Several common themes emerged from the study, most notably that these people valued accurate, compassionate and respectful media reporting.

\section{Suicide and the media: the state of current knowledge}

The study provides an interesting perspective on the topic of media reporting of suicide. To date, the vast majority of research in this area has examined the impact of media reporting of suicide ('media effects studies'). ${ }^{2}$ We reviewed the media effects studies that considered news and information media in 2001, ${ }^{3}$ and again in $2009 .{ }^{4}$ By the latter period, around 100 such studies had been conducted internationally. Collectively, these studies provide consistent evidence that incautious reporting of suicide can lead to imitative acts. Far-reaching, high-impact reporting (e.g. repeated stories, front-page stories) has been shown to be followed by 'spikes' in suicide rates. ${ }^{5,6}$ Detailed reporting of the method of suicide has been found to be associated with particular increases in deaths by the method described. ${ }^{7}$

The media effects studies provide firm evidence that a relationship exists between media reporting of suicide and subsequent suicidal acts. What they do not do, however, is 'drill down' to look at how news about suicide is generated, received and interpreted. Very little work has been done to shed light on the way in which stories about suicide are produced by media professionals, and on the way in which people who have been

†See pp. 228-232, this issue directly affected by suicide might shape them ('news production studies'). ${ }^{2}$ Similarly, relatively little attention has been paid to the way in which media messages are interpreted by audiences in general and by bereaved people in particular ('audience reception studies'). ${ }^{2}$ Chapple et al's study is novel in considering the perceptions and experiences of those who have been bereaved by suicide. ${ }^{1}$

\section{Guidelines on responsible reporting of suicide}

Concerns about the negative impact of irresponsible reporting of suicide have led to a proliferation of guidelines for media professionals. ${ }^{8}$ Four of these are mentioned by Chapple et $a l,{ }^{1}$ but there are many more - the International Association for Suicide Prevention's Suicide and the Media Task Force identified over 30 from around the world with minimal effort (www.iasp. info/media_guidelines.php). These guidelines have been shown to have a positive impact on reporting, particularly when they are developed and introduced with the cooperation of media professionals. ${ }^{8}$ In some cases, these guidelines are accompanied by complementary activities such as media awards for exemplary reporting in the area. ${ }^{9}$

These guidelines are not about censorship; instead they provide advice about how to report responsibly if a decision is made to run a story about an individual's suicide. Some of the recommendations in the guidelines draw directly on the evidence from media effects studies and relate to minimising the risk of copycat acts. For example, they urge journalists to moderate their coverage (because of the evidence that prominent stories may increase the likelihood of copycat acts) and to avoid explicit detail about the way in which the person died (because of the evidence that specific suicide methods may be copied). ${ }^{8}$

Other recommendations are based more on notions of good journalistic practice and common decency; the kinds of values that were the subject of the recent Leveson Inquiry. ${ }^{10}$ For example, many guidelines make reference to the fact that those who have been left behind after the death may be particularly vulnerable (e.g. at risk of self-harm themselves), and that any contact with them should respect their grieving process. The difference here is subtle - there is evidence from elsewhere in suicidology that those who have been bereaved by suicide are at heightened risk themselves, ${ }^{11}$ but there is no direct evidence from media-related 
studies that the bereaved are particularly likely to copy suicidal acts depicted in the media. The recommendation is not so much about any risk that may be associated with the content of a published story, but more about the potential impact of the process of gathering information from those who have recently lost someone to suicide.

\section{Perspectives on what is important in media reporting}

Chapple et al's ${ }^{1}$ study is interesting because it suggests that there may sometimes be tensions between what media guidelines recommend and what those bereaved by suicide believe is important, particularly in the case of recommendations that directly relate to minimising copycat acts. As noted, for example, the guidelines suggest that prominent reporting may be detrimental, particularly if it glorifies the death. For the bereaved, however, this sort of coverage may be seen as public recognition of their loved one and an appropriate memorial to his or her life. Similarly, the guidelines' suggestion that it is preferable not to provide in-depth information about the method of suicide may clash with the views of the bereaved. They may feel that including this level of detail is necessary, particularly in circumstances where they believe that the death would not have occurred had the means of suicide not been available.

It would not be reasonable to expect those who have been bereaved by suicide to be aware of the evidence base surrounding the influence of the media on copycat behaviours. It is not surprising, therefore, that what the guidelines say about how and how not to report on suicide may differ from what the bereaved may want to say about the person they have lost. It is worth considering what the best approach might be when the two imperatives clash, and the role that media professionals might play in this. There will be instances when minimising the risk of copycat acts should be paramount, but there will also be instances where a middle ground might be reached. For example, reports about people who have overcome suicidal crises have been shown to be associated with a protective effect in terms of copycat suicide, ${ }^{12}$ and journalists may want to consider sensitive ways of exploring this angle.

The recommendations that relate to sound journalistic practice seem to more consistently align with the views of those who participated in Chapple et al $\mathrm{s}^{1}$ study. These recommendations boil down to giving due acknowledgement to the feelings of the bereaved. This means respecting their privacy, and not pursuing a story if they do not want to publicly share their grief. In cases where they do wish to talk, they should be allowed to do so at their own pace. They should not be pressured, and should be given latitude to provide only the information they feel comfortable in disclosing. Reporting should be accurate and faithful to the details they provide.

\section{Conclusions}

Ultimately, everyone would like to see a reduction in deaths by suicide. Suicide prevention experts work towards this goal on a daily basis. Media professionals take their role in educating the public seriously, and the issue of suicide is one area in which they can confirm facts and dispel myths. People who have been bereaved by suicide often say that they do not wish to see others go through the same experience. With these common views in mind, it should be possible to ensure that media reporting about individual suicides is both respectful of the bereaved and unlikely to lead to copycat acts. As guidelines are developed or revised, consideration should be given to strengthening recommendations about respecting the bereaved and taking into account their needs.

Jane Pirkis, MPsych, MAppEpid, PhD, Anna Machlin, PGDipPsych, DPsych, Centre for Health Policy, Programs and Economics, Melbourne School of Population Health, University of Melbourne, Australia

Correspondence: Professor Jane Pirkis, Centre for Health Policy, Programs and Economics, Melbourne School of Population Health, University of Melbourne, Victoria 3010, Australia. Email: j.pirkis@unimelb.edu.au

First received 29 Dec 2012, final revision 17 May 2013, accepted 25 Jun 2013

\section{References}

1 Chapple A, Ziebland S, Simkin S, Hawton K. How people bereaved by suicide perceive newspaper reporting: qualitative study. Br J Psychiatry 2013; 203: $228-32$.

2 McQuail D. McQuail's Mass Communication Theory (5th edn). Sage, 2005.

3 Pirkis J, Blood R. Suicide and the media: (1) Reportage in non-fictional media. Crisis 2001; 22: 146-54.

4 Pirkis J, Blood R. Suicide and the News and Information Media: A Critical Review. Commonwealth of Australia, 2010.

5 Etzersdorfer E, Voracek M, Sonneck G. A dose-response relationship between imitational suicides and newspaper distribution. Arch Suicide Res 2004; 8: 137-45.

6 Hassan R. Effects of newspaper stories on the incidence of suicide in Australia: a research note. Aust NZ J Psychiatry 1995; 29: 480-3.

7 Fu K, Yip P. Estimating the risk for suicide following the suicide deaths of 3 Asian entertainment celebrities: a meta-analytic approach. J Clin Psychiatry 2009; 70: 869-78.

8 Pirkis J, Blood RW, Beautrais A, Burgess P, Skehan J. Media guidelines on the reporting of suicide. Crisis 2006; 27: 82-7.

9 Dare A, Andriessen K, Nordentoft M, Meier M, Huisman A, Pirkis J. Media awards for responsible reporting of suicide: experiences from Australia, Belgium and Denmark. Int J Ment Health Syst 2011; 5: 15.

10 Leveson B. An Inquiry into the Culture, Practices and Ethics of the Press. TSO (The Stationery Office), 2012.

11 de Groot M, de Keijser J, Neeleman J. Grief shortly after suicide and natural death: a comparative study among spouses and first-degree relatives. Suicide Life Threat Behav 2006; 36: 418-31.

12 Niederkrotenthaler T, Voracek M, Herberth A, Till B, Strauss M, Etzersdorfer E, et al. Media and suicide. Papageno v. Werther effect. BMJ 2010; 341: c5841. 